\title{
STRATIGRAPHY AND ANALYSIS OF INTERFACES FOR THE PRESERVATION OF ARCHITECTURAL HERITAGE
}

\author{
D.R. FIORINO \\ Department of Civil Environmental Engineering and Architecture (DICAAR), University of Cagliari, Italy.
}

\section{ABSTRACT}

The study contributes to the recognition of the central role of the interface in a restoration project. In fact, boundaries, joints and connections represent the key factor for understanding and interpreting the chronological sequence of the construction in a historical monument and they are the place where the contact of different entities can engender problems of connection and transmission, as well as material, chemical-physical, aesthetic or related to technological compatibility (structural, thermic and hygrometric). In the planning stage, they also intervene decisively in the principles of feasibility such as distinctness, reversibility, current expression and sustainability, which form the theoretical basis of the discipline. One particular case of interface is the one generated by erosion. The text presents the case of erosion of the urban walls of Cagliari, where the phenomenon has been faced by the creation of interesting integration interfaces in the course of time. Particularly, in the case of the 'Porta di Altamira', a scale of the degrees of erosion, useful for the planning of possible units of integration, has been studied. Based on the case study and the theoretical principles of the discipline, the research suggests the stratigraphic process as a standard methodology and operating criterion for the preservation and the restoration of interfaces and for the integration of gaps.

Keywords: chronologies of structures, compatibility, distinctness, integration of lacks, restoration.

\section{INTRODUCTION}

The overall objective of this research program is to contribute at the definition of a methodology for the analysis of the multilayered historical building, based on the strong conviction that the interface plays a major role in the restoration project. In fact, in the analytic process, it represents the key factor for understanding and interpreting the stratigraphic units and for the reconstruction of the building sequence. In the planning stage, it also intervenes decisively in the principles of feasibility such as distinctness, reversibility, current expression and sustainability, which form the theoretical basis of the discipline. However, these criteria are systematically disregarded in applications due to the inadequate treatment of interfaces. This attitude proves the common lack of realization of their importance. This is true both for historical interfaces and for the overlapping of old and new elements and materials.

In particular, scientific literature has already recognized the role of the stratigraphic conservation in the restoration project [1] and effectively highlighted the problems associated with the admixture of constructive techniques and the vulnerability - especially seismic - that comes from a complex multilayered architecture, such as those with a combination of load-bearing walls and elements in reinforced concrete [2]. Moreover, it is also important to consider all the elements introduced in previous restoration works, with the high increase in the number of discontinuities and internal interfaces; this condition has proved to be a high-risk factor for old architectures since it produces irreversible damage to historic structures, deeply changing the statics and the functional performance of the original building. In several case studies, this situation even required 'de-restoration' operations [3]. It is the case of inappropriate consolidations, waterproofing, specific high performance protective coatings that have proved to be incompatible, starting from interface surfaces.

(C) 2015 WIT Press, www.witpress.com

ISSN: 1743-7601 (paper format), ISSN: 1743-761X (online), http://www.witpress.com/journals DOI: $10.2495 / \mathrm{SDP}-\mathrm{V} 10-\mathrm{N} 5-755-766$ 
For these reasons, the study intends to give a personal contribution to the definition of shareable standards for the knowledge, description and parameterization of interfaces, starting from the available literature on the subject [4], and then proposing some new tools for the their investigation.

\section{BUILDING AS A NETWORK: THE ROLE OF INTERFACES}

Every building can be broken down into constructive elements, correlated among themselves by physical, chronological and immaterial elements. The minimum unit for the discretion of the building is undoubtedly the stratigraphic unit, understood as the smallest element able to represent all the descriptive properties, which characterize a monument: geometric, material, constructive, conservative and chronological.

The historical construction can be, therefore, represented and studied as the coordinated set of stratigraphic units (components) correlated among themselves by the relative interfaces. The term 'interface' means a physical place - point, area or surface - in which two or more qualitatively different entities (stratigraphic units) come into contact and can engender problems of connection and transmission, as well as material, chemical-physical, aesthetic or related to technological compatibility (structural, thermic and hygrometric).

Therefore, the building, intended as a 'network', has to be investigated not only through its stratigraphic units but especially through its nodal 'equilibrium', to be precise through the study of all the physical, chemical and aesthetic-formal reactions located in the interfaces.

Only in this way, the restoration project, awareness of interfaces processes, will be able to limit interferences generated by restoration activities, to contain the interfaces engaged by degradation phenomena, and to propose innovative solutions for interfaces of 'integration', both when it has the size of the 'gap' in the traditional sense and in cases of a wider architectural completion.

From the analysis of the technical data provided by the specialized literature and the reports provided by institutions of protection, it is quite evident that the overall success of restoration lies in the comprehension, interpretation and treatment of the interfaces [5]. This follows from the fact that the most frequent restoration activities involving cultural heritage concern the treatment of an interface or, more frequently, the creation of new ones. The first typology of intervention on interface relates not only to the sealing of physical discontinuities in the presence of elementary or complex crack patterns but also to the re-adhesion of the plaster to its building substrate and furthermore to the complex management of the surface-environment diaphragm. In addition, several categories of restoration works produce new interfaces. This is the case of the insertion of strengthening elements of wood or steel and the use of fibre-reinforced composite materials. Besides, the coat of protective materials on the surfaces induces modifications of matter and determines a change in the behaviour of the surface/environment joint. In the same way, the insertion or overlapping of technological elements for environmental control and energy saving as external or internal 'coats', waterproofing and thermal barriers and shields modify the boundaries of architectural layers. Developing the concept, also the placement of strata for accessibility, enhancement and usability of the historical heritage such as ramps and stairs, railings and intrusion barriers, technological equipment, etc. can be considered additional modern interfaces and vulnerable areas.

It is thus clear that the interface plays the role of:

- witness and dating element in the historical and chronological reconstruction of structures [6];

- migration node of structural stresses, element of specific vulnerability in the changing of the loads path induced by seismic actions, as well as a crucial point in the definition of strengthening and consolidation intervention techniques for improvement of the structural safety of the historic building heritage; 
- solution of continuity and interaction surface between 'traditional' materials (mortars, bricks, decrepit plaques, wood and iron) and 'restoration' materials (restoration mortars, resins, concrete, fibre-reinforced materials, steel and wood). For the latter, preferably qualified by their formal characteristics typical of contemporaneity, the relationship with the pre-existence is legitimated through the overlap-free modes. As a result, the 'physical joint' also assumes the dimension of 'temporary interface' between the old material and the contemporary intervention. This contributes actively to supporting the possibility of coexistence between 'old' and 'new';

- expression of the degree of sustainability in the transformation process in terms of: reversibility, authenticity, and environmental compatibility of the restored building;

- control of energy and material exchanges between indoor and outdoor environments.

Also, the short list indicated above clarifies how the overall good outcome of the restoration process resides exactly in the comprehension, interpretation and treatment of interfaces.

\section{A MULTIDISCIPLINARY METHODOLOGY FOR THE KNOWLEDGE, MONITORING AND RESTORATION OF HISTORICAL INTERFACES}

The physical interface, being a connection, is also a place of interchange of knowledge where physicochemical and thermodynamic processes occur and where historical, architectural and aesthetic issues get together. Therefore, the study of interfaces is a multidisciplinary one and the effectiveness of design solutions depends on the degree of interdisciplinary relations that the research is able to activate.

For that reason, a protocol of investigation has been codified, divided into the following operational units:

- identification and parameterization of the 'historical' and 'restoration' stratigraphic interfaces by means of an innovative data sheets included in a relational database, web-based and interoperable with existent international databases;

- detection of photogrammetric 3D interface sample, their characterization in terms of formal, material, structural and thermic aspects;

- definition of standards for the representation and description of interfaces to allow the comparison of the parameters measured with those provided by other international scientific communities. For the same objectives, the description and calibration of the ND diagnostic protocols (thermographic, sonic and georadar) are included, no longer applied to the single stratigraphic units - because their characterization has already been abundantly approached by international literature - but dedicated to the definition of the interface behaviour and to the long-time monitoring of possible phenomenon typical of the 'border' points such as detachment variation, crack outlines, etc.;

- interpretation of the degradation due to 'interface' phenomena and of the interfaces of 'degradation';

- testing of 'ancient-new' interfaces and stratigraphic 'integration' sustainable from the aesthetic, formal and technological points of view, reversible in terms of conservation and reliable in terms of performance.

Considering the extent of the outlined research, it is obvious that it cannot be the result of the work of one researcher, but the product of the stratification of knowledge obtained over time, with the multidisciplinary contribution of several working groups. This methodology has been tested within the university teaching methods, thanks to an agreement between the Department of 
Civil-Environmental Engineering and Architecture and the Educational Services of the Superintendency for the Architectural and Landscape Heritage (BAPSAE) of Cagliari and Oristano (Sardinia, Italy). Two restoration workshops and some graduation thesis were carried out within this agreement, taking the antique walls of Cagliari as a case study.

\section{INTERFACES BY EROSION: THE CASE OF THE URBAN WALLS OF CAGLIARI (SARDINIA ITALY)}

The walled city, with its wall palimpsest, its stratified urban texture and the formal-architectural identity of the intramural structures, still represents a transversal document of the history of architecture - not only military - and the history of restoration, with an undoubted international importance. Based on this awareness, a systematic scientific study of the curtain walls started in 2013. The need to document those parts of the walls that are still authentic also derives from the fact that recent works carried out on consistent portions of these structures have already cancelled some considerable stratifications, particularly those referred to historical restoration works. Further planned interventions threaten the conservation of other parts of the city walls.

\subsection{Origin and evolution of the urban walls in Cagliari}

The existence of a fortified nucleus in the city of Cagliari was first mentioned in 1217, with reference to today's quarter of Castello - indicated in various documents with the name Mons de Castro or also Castel di Castro - founded by the Pisans on the hill which had probably housed the castrum of the Roman Carales, behind the pre-existing port settlement of Bagnaria.

Once the town of Santa Igia was destroyed and the Giudicato of Cagliari was overthrown, as of 1257 the citadel was expanded by the Pisans by creating the two appendixes of Villanova and Stampace, built at the same time following a unitary plan, which can be connected to the structure used in those same years for the foundation of the Tuscan 'terre murate', whose layout reminds us of the iconography of a golden eagle with a cross on its chest, recurrent in medieval pro-imperial cities such as Pisa. The primitive Pisan wall system was then strengthened and modified over the centuries in response to the new weapons used and the resulting defence techniques, making Cagliari one of the safest military and commercial bases in the Mediterranean, until the fortified town was decommissioned.

In 1323, the Aragonese started to modernize the primitive Pisan curtain walls, characterized by the imposing towers of San Pancrazio (1305), of the Elephant (1307), of the Lion and Santa Lucia, but the real changes took place in the first half of the 16th century, after pieces of ordnance were introduced. To strengthen the north-western sector of the city, which could be easily attacked because of the land morphology, viceroy Joan Dusay created two new bastions, widely criticized from a technical-operational point of view, one in the area of San Pancrazio (1501-1503) and another in the area of Santa Croce.

The arrival in Sardinia of engineer Rocco Capellino from Cremona (1552-1572), first, and of engineers Jacopo and Giorgio Paleari Fratino from Ticino (1563-1578), later, along with other expert technicians such as Alessandro Febo and Giovam Battista Cairati, led to the introduction of high-level 'modern' architectural and military solutions in the defensive system of the main fortified city in Sardinia, consistent with the time's most updated essays, which reveal an accurate study of the local morphology and a wise use of local building materials. In particular, the Palearis introduced substantial changes to San Pancrazio's tenaille line, to the shape of the bastion of Santa Croce and to the entire western front of the Castle, for a better 'correspondence' between artilleries [7].

From 1720 to the Italian Unification, the annexation of Sardinia to the Savoy territories entailed a new season of transformations to the fortified city of Cagliari, interventions which were planned and 
carried out by engineers belonging to the Royal Unit of Military Engineering (Antonio Felice De Vincenti, Augusto La Vallèe and Carlo Barabino), mainly in the north-western part of the city (area of the Royal Arsenal, the Citadel of Buoncammino and the Bastion of San Filippo). These include the creation of the Porta d'Apremont, finished in 1741 and demolished in 1914 to allow the passage of the tram line.

The decommissioning of the military stronghold, which took place in 1866, marked the legitimation of significant demolitions of bastions and walls, considered an obstacle to the hoped-for expansion and modernization of the city. Only in 1902 will the monumental character of the curtain walls and defence towers in Cagliari be acknowledged by the enlightened personality of engineer Dionigi Scano, creator and promoter of a brave campaign of philological renovations and restorations aimed at freeing the Pisan towers and wall curtains, marking a particular moment in the history of restoration in Sardinia. Finally, the interventions by Libero Cecchini and Piero Gazzola to reconvert the areas of the Royal Arsenal into the Citadel of Museums date back to 1957-1979.

\subsection{Degree of erosion, interfaces and integration of gaps in the urban city walls}

Cagliari walls were built mainly with local limestones outcropping on the hills situated around the city where these stones had been quarried from roman period until the fifties in the XXI century. These local lithotypes are Pietra Forte, Tramezzario and Pietra Cantone, miocene rocks of calcareous nature.

Pietra Forte, due to its agreeable aesthetic aspect and good geomechanical properties, is an excellent building stones mainly used for structural purposes. Pietra Cantone, on the contrary, is characterized by poor technical features and widespread forms of decay such as lacks, alveolarization, granular disintegration with differential withdrawal of the stone surface, reason why it was very often protected by plaster [8].

The walls are predominately affected by chemical weathering due to rainwater which contains natural and artificial salt and by dry deposition due to particulate (PM) so now the walls show erosion, loss of details and black crusts.

The intense erosive phases are testified by a widespread activity of repairing, integration of the gaps and substitution of masonry patterns which came about both in the growth and in the transformation stage of the wall perimeter, as well as in the various restoration sites which have occurred from the beginning of the 1900s to today. The study of integration of the gaps generated by erosion allows the reconstruction of an interesting history of local ways of restoration of undoubtedly methodological interest.

The most widespread system and, in time, the most refined one is that which has been built with the insertion of clay bricks. The modular elements allow, in fact, an easy adaptability to the geometry of the gap, both in the width of the surface as well as in the depth of the erosion to fill in. This method allows one not to alter the interface of the gap through a simple stratigraphic operation of addition. Beyond this, the integration is easily distinguishable and respects the criteria of physical and mechanical compatibility as well as the formal ones. Naturally, the elements must be joined with lime mortar.

In the course of time, other solutions have been attempted, such as the introduction of other stone elements with similar geological properties, but with different surface treatments. The aim was that of making the additions distinguishable from the antique stones, but some solutions has strong impact of the perception of the old curtains, as it happens for the reparations made with stones moulded as tiles. Some samples are in Fig. 1.

An interesting palimpsest of these integrations can be recognized in the Altamira Gate, in the area of the Tower of San Pancrazio, the northern entrance to the city, which has always represented the 

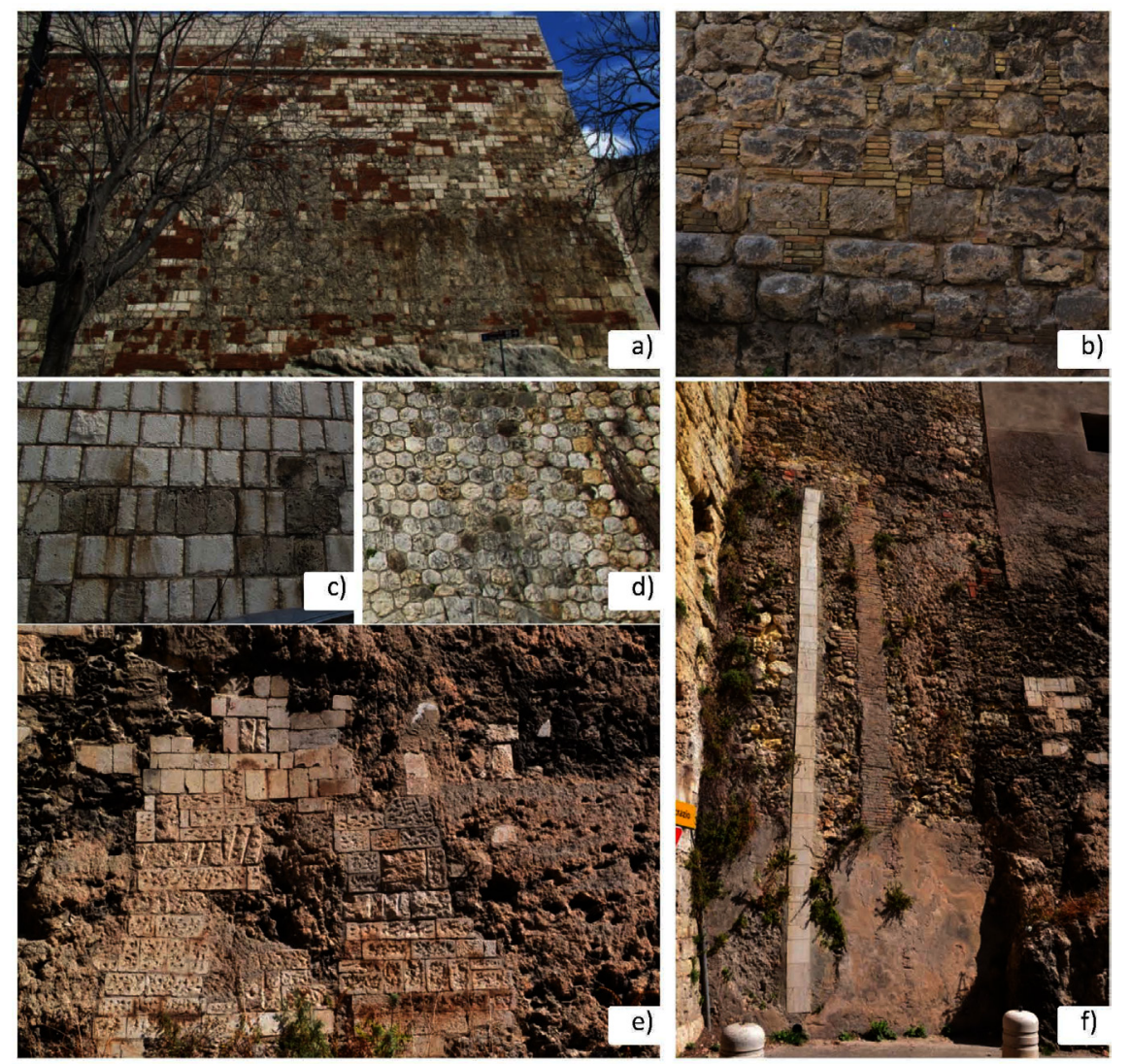

Figure 1: Different modes of integration of erosion gaps by using clay bricks as in picture (a) and (b), or by stone elements with different shapes as in picture (c) and (d), or with different surface treatments as in case (e), or with stones moulded as tiles as in case (f).

most vulnerable part of the walled town, since it opened directly onto the hinterland. This is why this area is one of the most stratified portions of the city walls, from the Pisan period to the crucial 19th century restorations [9].

The gate, called 'D'Altamira' from the name of the Viceroy who had it erected in 1692, still appears partly painted in a photograph from the beginning of the 1900s, which confirms the fact that the lithotype 'Pietra Cantone', particularly vulnerable to the atmospheric agents, was always protected with a plaster coat. Subsequently, with the loss of the plasterwork and the erosion of the stones, the parts most decayed and vulnerable from a structural point of view were integrated with clay bricks, with particular attention to the outside facing of the wall and to the corners, with quoins shaped as a zipper. This elegant intervention shows the care taken of the monument during restoration works in the past. The results of the successive integrations with stone wedges are of less formal quality, even if they have the same technical-functional effectiveness and formal recognition.

In 2013, thanks to the already quoted agreement between the Department of Civil-Environmental Engineering and Architecture and the Educational Services of the Superintendency for the Architectural and Landscape Heritage (BAPSAE) of Cagliari and Oristano, the eastern side of the gate and its wall face has been analysed in detail. 
The study integrated between research and teaching started with the photogrammetric survey and the graphic restitution of the wall face. On the basis of the metric survey thus conducted, the stratigraphic units and several wall types were classified. Great attention was shown in drawing the single ashlars, as the detailed graphic reproduction of the wall texture typical of archaeological surveys can help in becoming aware of the material consistency of the artefact, of its metric and material discontinuity, and therefore in understanding its building nature. Furthermore, the study identified the units of integration descended by reparation works owing to the erosion of the surface.

However, the most significant analysis carried out on the monument was the definition of a scale for the evaluation of the erosion degrees; this scale has been tested on the different materials of the gate, as shown in Fig. 2.

This useful scale of values is able to classify the gaps created by the erosion accordingly to the depth of the lack and to the general state of risk brought about by it. In fact, the parameter designed by this research considers not only the level of erosion reached by each constructive element, analysed stone by stone, but also takes into account the possibility of a structural collapse of the outer layer due to the reduction of the bearing section of the wall, which this element belongs to.

It is believed that such parameterization may be an effective tool for the evaluation of the need for integration and for the critical choice of the same modes of restoration, according to the principle of minimum intervention. In fact, the urgency to substitute and integrate the gaps will be the highest only for those stones whose damage puts the stability of other parts of the building at risk. A purely protective and conservative intervention may, on the other hand, be studied for the portions whose erosions do not produce further degradation, therefore, limiting the creation of new interfaces and new borders where it is not highly necessary.

\section{CRITERIA FOR PRESERVATION AND RESTORATION OF INTERFACES AND FOR THE INTEGRATION OF GAPS}

The stratification method and the analysis of the interfaces are part of the knowledge process, but they should also be the main principle of every restoration design, able to assure future recognition in interventions of addition or subtraction of material, which occurred in the restoration works. The case study illustrated above highlights the importance of the treatment of interfaces in the restoration project. In particular, it is evident the importance of maximizing the conservation of interfaces, as tangible witness of building growth or transformation, reducing the impact of performance adjustment. At the same time, mimetic attitudes have to be minimized, avoiding general coatings of the interfaces edges. Moreover, restoration must emphasize new interfaces and new edges by means of recognizable techniques, compatible in terms of chemical, physical and aesthetic point of view.

\subsection{The treatment of existing interfaces}

In a restoration project the stratification interfaces must be respected as much as possible and especially the borders of each stratigraphic unit, which testify a physical and chronological relationship between the different parts of the historical building. Such signs represent, in fact, the tangible evidence of the history of construction or the transformations that the building has undergone over time. In particular, the treatment of an interface must respect the material authenticity of the borders and avoid the binding of the stratified elements, following a specific interpretation of the architecture. In fact, this interpretation may also change in time in relation to the advancement of studies and to the progress of the investigation techniques. The restoration task is, therefore, that of freezing the existing situation, to protect it from possible forms of degradation and to fully transmit it to future studies, leaving the given materials and signs understandable and unaltered [10]. 

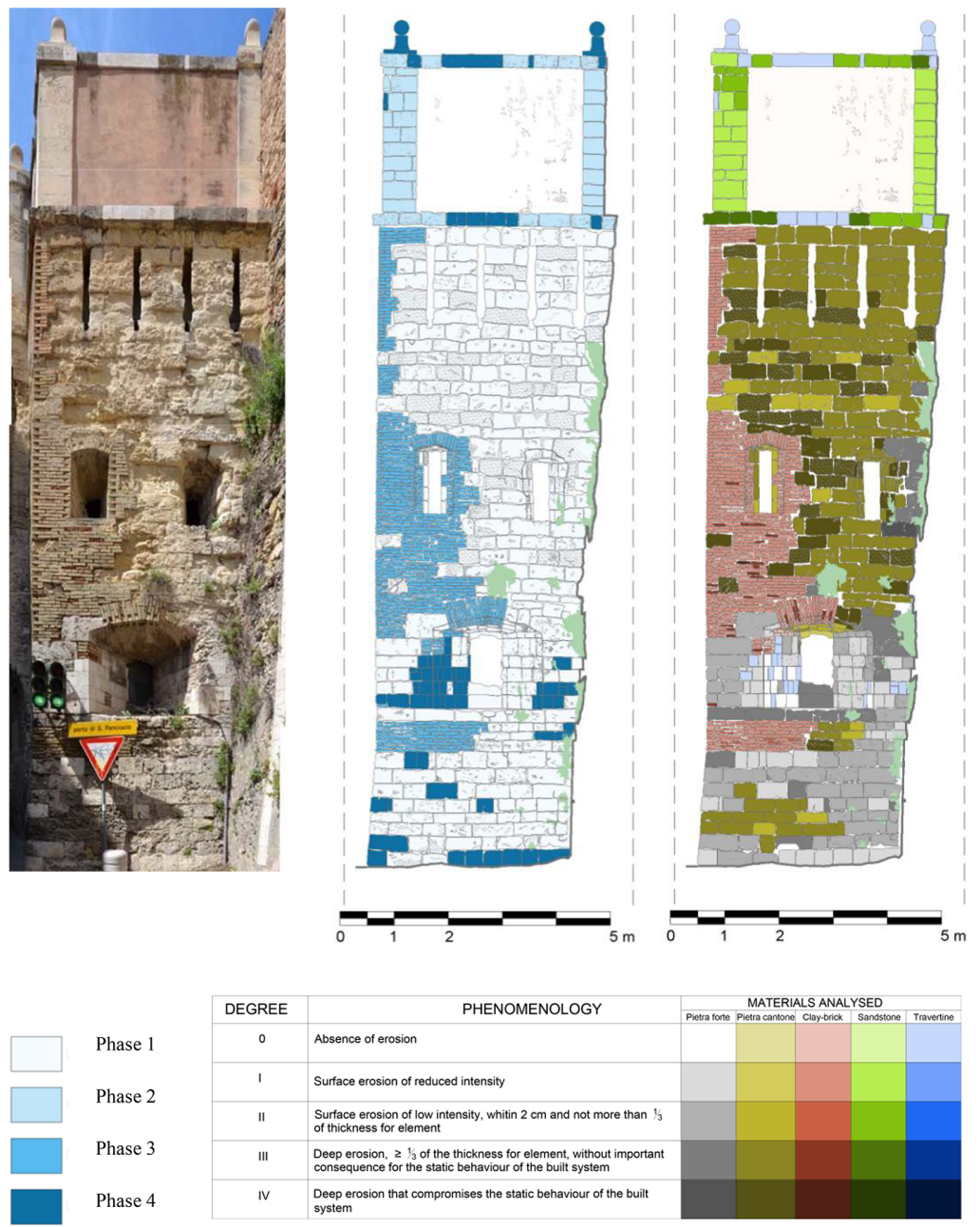

Figure 2: Cagliari, urban door called D'Altamira, study of the stratification and interfaces of integration owing to the erosion and definition of the current levels of erosion, preparatory to the restoration plan (drawing produced in the Integrated Course of Restoration and Building technology, Master Degree in Architecture, University of Cagliari, AA. 2012/2013, students A. Manca, D. Orrù, F. Farci and F. Savona).

Nevertheless, such a theoretical approach seems to be unattainable because each intervention, even the most careful and limited, introduces permanent physical and aesthetic modifications onto the object of restoration. For this reason, it is necessary at the beginning of every project to prepare the so-called 'map of the signs' to protect, that is the indication of those traces of physical and chronological discontinuity, whose perception must be assured in time. At the same time, much attention must be given to not conform the restored building to the contingent stratigraphic reading, making it a didactic map of this temporary interpretation.

It is necessary, therefore, to harmonize the critical project with the appropriate operative techniques to allow the maximum conservation of the identified stratification [11]. 
In the first place, it is necessary not to change the appearance of the surface materials, avoiding covering masks which can modify the perception and the legibility of the historical signs. Therefore, generalized and level out interventions are to be avoided, such as the entire covering of surfaces, the complete substitution of the plaster, the total and undifferentiated joint sealing. The same attention must be given to the borders of the negative interfaces and to false borders, which should never be covered or altered in their geometry and in their consistency.

The treatment of the stratification interfaces within the restoration project should be as homogeneous as possible to avoid the introduction of hierarchical degrees between the interfaces, for example, highlighting some of that and neglecting others: this would be like an arbitrary selection of the historical occurrences of the building which these interfaces refer to.

Regarding the interfaces of degradation, it is necessary to mitigate the effects of the decay without cancelling, blurring or covering the patina of time, the stratifications and the borders of contact.

In the integration process, the creation of new borders and of new-antique interfaces is also to be checked with accuracy, trying to respect the character of the building that has been acquired in time without changing it radically. Unfortunately, in common practice, the unjustified tendency of the creation of false borders has been established, tied to arguable aesthetic parameters, which tend to highlight partial and arbitrary aspects of building details, whose interpretation appears so unbound to the context and deformed in meaning. In Fig. 3, a good sample of integration of stratified architectural surfaces is shown.

\subsection{New interfaces}

Where it is necessary to integrate an artefact by filling in a gap, or to insert new elements necessary to provide for new structural, functional or distributive needs, one is placed with the age-old problem
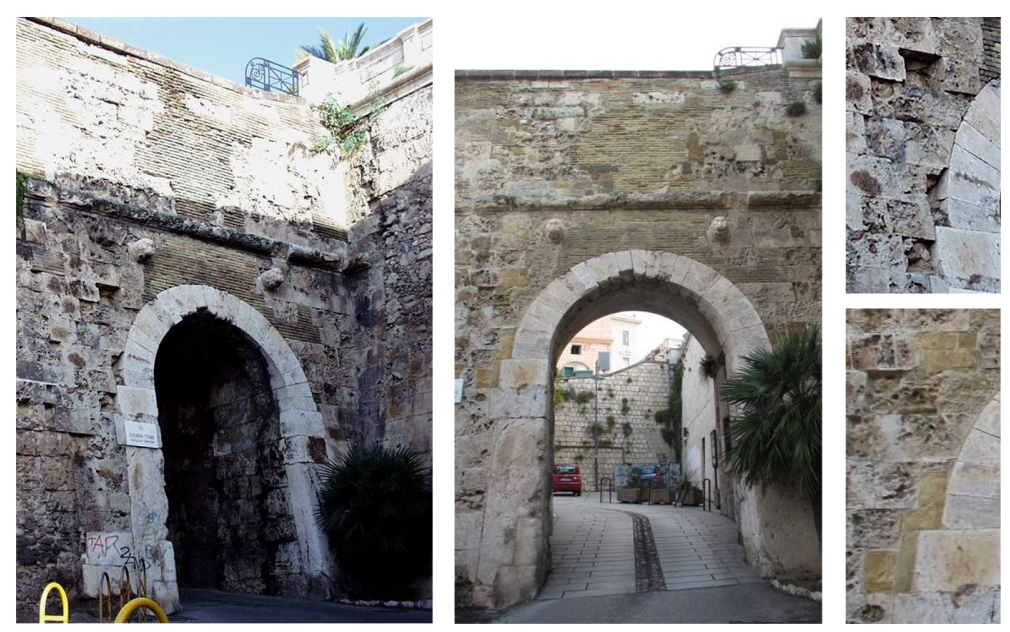

Figure 3: Cagliari, the Lion Gate before and after its restoration in 2007. The images show an interesting careful conservation of the stratifications and of the interfaces maintain the sequence of constructive events and the phases of restoration works clear even in the future. The integration in the areas of the greatest erosion was made by wedges in limestone from Segariu (CA). 
of how to integrate it, whether from the technical-operative aspect or from the purely aestheticformal perspective.

It is held that, even in this case, the stratification criteria can contribute in a coherent and efficient way to the planning of the integration work of restoration, as well as direct the critical choices and the operating modes connected with the possible interventions of removal and substitution eventually necessary.

The integration must be planned as one of the stratification units of the monument and, with it, the interface between the new element and the original one. The border between antique and new constitutes, in fact, the place in which the temporary relations manifest themselves, and the match of physical, chemical and aesthetic-architectural compatibility is played.

What are, therefore, the criteria for treating historical interface?

The first thought regards the sealing of the joints. The use of the technique of the 'undercut' does not guarantee in itself an optimal result. Figure 4 shows, for example, how the choice of the colour of the mortar used for the joint sealing can notably modify the formal result of the integration.

The stone cladding and the insertion of patches and wedges, on the contrary, on one hand reduce the visual impact of the new interface, on the other hand, chance the pattern of the outside facing of the wall, falsifying the reading of the constructive techniques and preventing the possibility to begin new archaeometric investigations about the historical walls, as illustrated in Fig. 5. In this case, the distinction of the elements inserted and the conservation of the authentic stones in their position, limiting the displacements to a minimum and avoiding the reuse of naked elements for the integration of the gaps, proves to be very important. In fact, the new texture created with antique material would be, from the archaeometric point of view, a false imitation of the antique appearance, with the
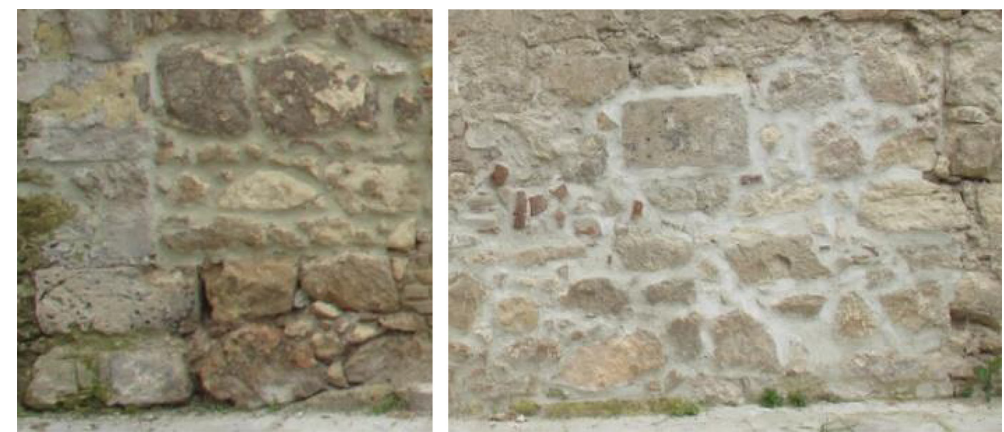

Figure 4: Integration of the gaps due to the erosion of the joints of mortar through the use of the same material but with a different colour.
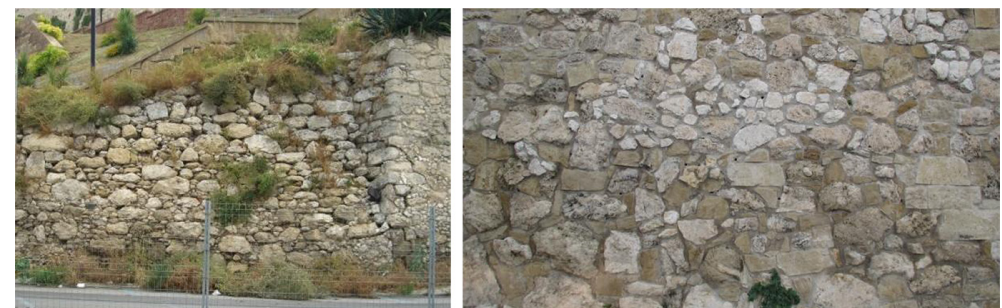

Figure 5: Cagliari, Cammino Nuovo bastions, the masonry before and after the integration of the gaps due to the erosion of the joints of mortar through the use of stones and wedges in limestone from Segariu (CA). 
consequent alteration of the successive stratigraphic reading. This is even more valid in relation to the possible completion of decorative mouldings and cornices. Even preferring the non-integration and the conservation of the gap, it could be necessary to repair the elements to contain the phenomenon of degradation or to guarantee technological or functional aspects. In this case, the recognition of the integrated element must be ensured, together with respect to the formal and chromatic homogeneity of the whole. Sometimes, the theoretical fury of recognizability brings to the realization of monstrous wall face for which the restoration would constitute an ulterior formal aggression rather than reparation.

A good sample of respectful integration is illustrated in Fig. 6.

When the gap obtains architectural dimensions, as showed in Fig. 7, or when entire structures must be inserted, serious attention must be paid to the design of the integrated element, which must be recognizable as a contemporary stratification unit, as well as to the borders that rule the relationship between the new element and the antique material. Such attention must be placed both in the project phase with the executive definition of the interfaces, as well as in the construction phase, where precise operative regulations must be punctually be defined by the director of the worksite. Also demolitions, when necessary, must be treated as negative stratigraphic units, well described in documents, but also recognizable in the building.
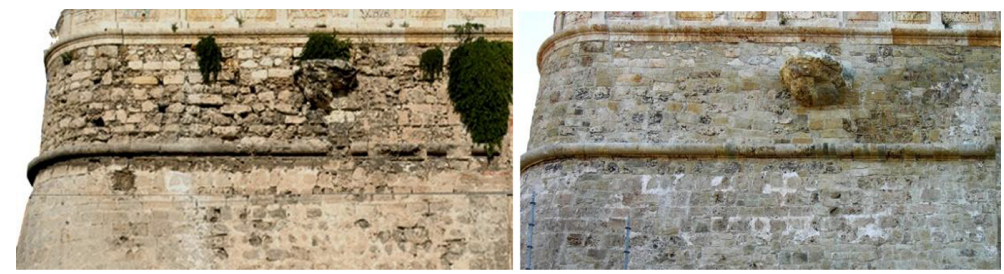

Figure 6: Cagliari, Bastione dello Sperone, the masonry before and after the integration of the gaps due to the erosion of the joints of mortar and the completion of the cornice through stones of different colour to assure the distinction of the new elements with respect to the old ones.

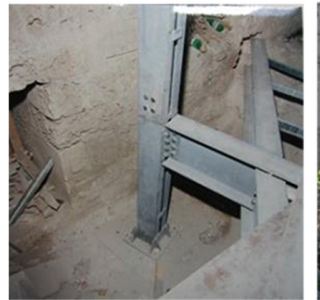

(a)

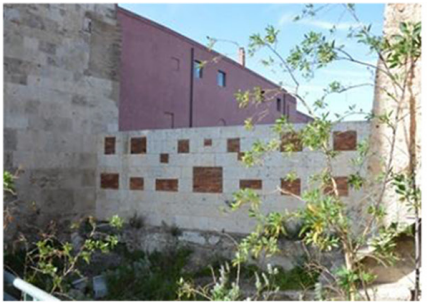

(b)

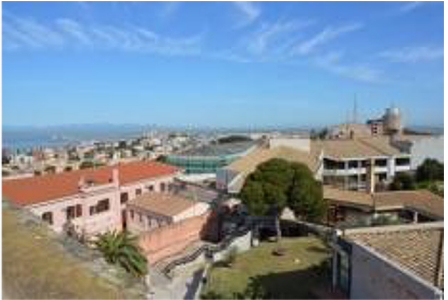

(c)

Figure 7: Technical, architectural and urban stratigraphic unit of integration added during the restoration works for the reuse of San Pancrazio site in Cagliari: (a) Dusay's stronghold, support of new structures in steel at the antique rocky basement by means of a slab (G. Tola); (b) San Pancrazio courtyard, new wall dressed with recognizable decorative element inspired in the integrative phase with bricks adopted to the rest of the antique wall portions (D. Scano); (c) Citadel of Museums as contemporary integration (P. Gazzola, L. Cecchini) about the area of the antique tenaille of San Pancrazio. 


\section{CONCLUSIONS}

The respect of interfaces represents a key point in the process of cultural heritage conservation. An improper treatment of historical buildings discontinuities, their loss or alteration, can definitively destroy ancient architectural signs and preclude the possibility to improve the knowledge of the ancient buildings in future years. The main goal of this research programme concerns the investigation on different kinds of interfaces, the analysis of the various techniques adopted for their restoration over time and the critical definition of a multidisciplinary approach for their preservation.

In fact, the cooperation of several disciplines seems to be not only relevant but essential to make informed choices regarding materials, aesthetic and technological solutions, both in the case of restoration and in the 'ancient-new' overlapping.

Many efforts have to be done in the future in this research topic. One of the possible further study is the development of models and parameters able to understand and manage mechanical, chemical and physical behaviour at the interfaces and to reduce the subjectivity related to the damage assessment. The described scale for the assessment of erosion degree demonstrates the utility of this kind of tools to support restorers in the decisional process and, consequently, to increase the awareness of restoration choices.

\section{REFERENCES}

[1] Doglioni, F., Ruolo e salvaguardia delle evidenze stratigrafiche nel progetto e nel cantiere di restauro, Arqueologìa de la Arquitectura no. 1, Università dei Paesi Baschi, Vitoria-Gasteiz, pp. 113-130, 2002.

[2] Gilento, P., Parenti, R. \& Vecchi, A., Archeologia dell'architettura e rischio sismico, Archeologia dell'Architettura, All'insegna del Giglio: Firenze, 2008.

[3] Fiorino, D.R., San Fruttuoso. Studi, restauri, allestimenti museali, Ggallery: Genova, 2012.

[4] Brogiolo, G.P. \& Cagnana, A., Archeologia dell'architettura: metodi e interpretazioni, Archeologia dell'Architettura, All'Insegna del Giglio: Firenze, 2012.

[5] Quendolo, A., Permanenza e leggibilità dei dati materiali: alcune riflessioni sul ruolo della conoscenza stratigrafica per la conservazione del potenziale informativo del costruito, Archeologia dell'Architettura no. XI, All'insegna del Giglio, Firenze, pp. 1-8, 2006.

[6] Fiorino, D.R., La stratigrafia urbana, Proposte per Stampace. Idee per un piano di conservazione del quartiere storico cagliaritano, eds. Giannattasio, C. \& Scarpellini,P., Gangemi: Roma, pp. 69-74, 2009.

[7] Pirinu, A., Il disegno dei baluardi cinquecenteschi nell'opera dei fratelli Paleari Fratino, All'Insegna del Giglio, Documenti di archeologia postmedievale: Firenze, 2013.

[8] Fiorino, D.R., Giannattasio, C., Grillo, S.M. \& Vacca G., Conservation and valorization of historical building: the case-study of Stampace quarter in Cagliari (Sardinia, Italy), Proceedings of the 3th International Conference on Heritage and Sustainable Development, eds. R. Amoêda, S. Lira \& C. Pinheiro, Green Lines Institute: Barcelos, vol. 3, pp. 1777-1786, 2012.

[9] Fiorino, D.R., Stratigraphic evidence in the ancient urban walls of Cagliari (Sardinia-Italy). WIT Transactions on the Built Environment, 143, pp. 257-268, 2014. doi: http://dx.doi. org/10.2495/dshf140221

[10] Bellini, A., Che cos'è il restauro. Nove studiosi a confronto, ed. B.P.Torsello, Marsilio: Venezia, pp. 21-24, 2005. 